\title{
Association between serum ca-125 levels and severity of pre-eclampsia: a case-control study conducted in a tertiary care centre, West Bengal
}

\author{
Bijoya Mukherjee, Amiya Das*
}

Department of Obstetrics and Gynecology, Bankura Sammilani Medical College, Bankura, West Bengal, India

Received: 29 July 2020

Accepted: 05 September 2020

\section{*Correspondence:}

Dr. Amiya Das,

E-mail: amiyadas0032@gmail.com

Copyright: (C) the author(s), publisher and licensee Medip Academy. This is an open-access article distributed under the terms of the Creative Commons Attribution Non-Commercial License, which permits unrestricted non-commercial use, distribution, and reproduction in any medium, provided the original work is properly cited.

\begin{abstract}
Background: Screening test for pre-eclampsia has been a topic of extensive research in last few decades, and to identify a cost effective and accurate one is of immense importance. This study was conducted to determine an association between serum CA-125 levels and severity of pre-eclampsia, and thus to specify clinical utility of this biochemical marker in prediction, diagnosis and follow-up of pre-eclampsia.

Methods: A case-control study involving 40 women with non-severe pre-eclampsia, 40 women with severe preeclampsia and 40 healthy pregnant women matched for age, parity and gestational age at enrolment were taken in a tertiary care centre in West Bengal.

Results: The CA-125 levels in three categories of participants were: normotensive (15.76 \pm 2.95$)$, non-severe preeclampsia $(26.98 \pm 2.28)$, severe pre-eclampsia $(44.99 \pm 11.23), \mathrm{p}<0.001$. CA-125 levels correlated positively with systolic blood pressure $(r=0.78, p<0.001)$, diastolic blood pressure $(r=0.79, p<0.001)$, negatively with platelet levels $(\mathrm{r}=-0.67, \mathrm{p}<0.001)$ and with birth weight of baby $(\mathrm{r}=-0.54, \mathrm{p}<0.001)$. When cut-off for serum CA-125 levels was accepted as $35 \mathrm{IU} / \mathrm{ml}$, the sensitivity and specificity of the marker was found to be $92.1 \%$ and $97.1 \%$ respectively. Positive predictive value $95.5 \%$, Negative predictive value $94.4 \%$.

Conclusions: We can infer from this study that maternal serum CA-125 levels are associated with pre-eclampsia and its severity. As it is much more available and less expensive, it seems to be a promising as a screening test.
\end{abstract}

Keywords: Association, CA-125, Pre-eclampsia

\section{INTRODUCTION}

Pre-eclampsia is the leading cause of maternal and fetal mortality and morbidity worldwide, affecting $5-10 \%$ of all pregnancies. ${ }^{1}$ It is clinically diagnosed as systolic blood pressure $\geq 140 \mathrm{mmHg}$ and/or diastolic blood pressure $\geq 90 \mathrm{mmHg}$ on at least 2 occasions 4 hours apart and/or proteinuria $>300 \mathrm{mg} / 24$ hours or in the absence of proteinuria presence of any of the followingthrombocytopenia <1 lac/ $\mu \mathrm{l}$, headaches and visual disturbances, renal insufficiency (serum creatinine levels $>1.1 \mathrm{mg} / \mathrm{dl}$ ), impaired liver function (blood levels of transaminases elevated twice the normal concentration), presence of pulmonary oedema. The WHO estimates that $16 \%$ of maternal deaths are due to hypertensive disorders and over 100,00 women die from pre-eclampsia globally, with a higher incidence in developing countries $(2.8 \%)$ than developed countries $(0.4 \%)$. $^{2,3}$

It causes ischaemic end-organ damage due to diffuse endothelial dysfunction affecting eye, brain, kidney and placenta. The most accepted theory of pathogenesis is defective trophoblastic invasion of placenta into maternal decidua, causing chronic inflammation and altered vascular reactivity. ${ }^{4}$ Resultant maternal adaptation to this abnormal immunologic tolerance of pregnancy is immune response against placenta and even paternal antigens on fetus resulting in placental hypoxia and secreting inflammatory mediators acting on endothelium. One such mediator is CA-125. ${ }^{5}$ 
CA-125 is a glycoprotein antigen expressed from foetal chorion, amniotic fluid and maternal decidua during the $1^{\text {st }}$ trimester and postpartum period, returning to normal levels during $2^{\text {nd }}$ and $3^{\text {rd }}$ trimester. It is a valuable marker for several benign and non-gynaecological conditions also. It is cheap, easily accessible- hence can provide a wide range of clinical use, while biomarkers like sFlt-1, PIGF, PAPPA (evaluated in $1^{\text {st }}$ half of pregnancy and $3^{\text {rd }}$ trimester) are costly and not much in vogue. ${ }^{6,7}$ However, the use of CA-125 in obstetrics is experimental and under extensive research which requires multicentric studies. ${ }^{8}$

\section{METHODS}

This study was approved by the Institutional Review Board and Ethics Committee of Bankura Sammilani Medical College where the study was conducted in the Department of Obstetrics and Gynaecology and Department of Biochemistry from May 2019 to December 2019. Written informed consent was obtained from all participants.

The study groups included 40 healthy pregnant women, 40 women with non-severe pre-eclampsia and 40 women with severe pre-eclampsia. They were matched for age, parity and gestational age at enrolment. Our study comprised of pregnant females who visited our hospital from 28-40 weeks of gestation. The healthy pregnant women were recruited at routine antenatal care and were excluded if any complication developed later. All participants were followed up till delivery with records of maternal and neonatal outcome.

Pre-eclampsia was diagnosed and classified according to the ACOG guidelines. Pre-eclampsia was divided into non-severe and severe categories. Non-severe preeclampsia was defined as $\mathrm{SBP} \geq 140 \mathrm{mmHg}$ and/or $\mathrm{DBP} \geq 90 \mathrm{mmHg}$ on at least 2 occasions 4 hours apart and presence of proteinuria $>300 \mathrm{mg} / 24$ hours. Severe preeclampsia was defined as $\mathrm{SBP} \geq 160 \mathrm{mmHg}$ and/or $\mathrm{DBP} \geq 110 \mathrm{mmHg}$ and presence of any of the following- proteinuria $>5 \mathrm{gm} / 24$ hours, headaches and visual disturbances, pulmonary oedema, upper abdominal pain, increased levels of transaminases twice the basal levels, serum creatinine $>1.1 \mathrm{mg} / \mathrm{dl}$, oliguria, thrombocytopenia $<1 \mathrm{lac} / \mu \mathrm{l}$ or foetal growth restriction.

Patients with diabetes mellitus type II, renal disease, obesity (BMI>30), peripheral vascular disease, liver cirrhosis, multiple gestations and symptomatic infectious diseases were excluded. All patients underwent pelvic USG to rule out any ovarian tumours, endometriosis or uterine fibroids in pregnancy.

In our study, venous samples were collected when the patients presented for the first time for evaluation and before initiation of any treatment. Serum CA-125 levels were estimated with the standard ELISA technique. 24hour urine samples were collected from each participant to determine protein excretion.

\section{Statistical analysis}

The collected data were analyzed by Statistical Package for Social Sciences (SPSS version 20). Data were expressed as mean \pm standard deviation or percentages where appropriate. Parametric variables of two groups were compared by independent samples t test, while oneway ANOVA was used to compare the parametric variables of three groups. The possible relationship between a particular biochemical parameter and stage or grade was evaluated by Pearson correlation test. Predictive power of CA-125 for preeclamptic pregnancies was determined by Chi-square test and the selectivity of this biochemical parameter was demonstrated. All significances were reported at $\mathrm{p}<0.05$.

\section{RESULTS}

Table 1 compares the clinical characteristics of the three study groups.

Table 1: Clinical and demographic characteristics of participants $(n=120)(M e a n \pm S D)$.

\begin{tabular}{|lllll|}
\hline & Normotensive & Non severe preeclampsia & Severe pre eclampsia & P value \\
\hline Ca125 & $15.76 \pm 2.96$ & $26.97 \pm 2.28$ & $44.99 \pm 11.27$ & 0.001 \\
\hline Systolic blood pressure & $122 \pm 9$ & $148 \pm 5$ & $168 \pm 9$ & 0.001 \\
\hline Diastolic blood pressure & $78 \pm 7$ & $96 \pm 5$ & $112 \pm 5$ & 0.001 \\
\hline platelet & $1.92 \pm 0.18$ & $1.74 \pm 0.06$ & $1.58 \pm 0.07$ & 0.001 \\
\hline Birth weight & $2.78 \pm 0.27$ & $2.47 \pm 0.14$ & $2.20 \pm 0.28$ & 0.001 \\
\hline parity & $1.93 \pm 0.69$ & $1.28 \pm 0.45$ & $1.23 \pm 0.42$ & 0.001 \\
\hline Urine protein 24 hours & $0.18 \pm 0.06$ & $1.71 \pm 0.47$ & $5.9 \pm 1.13$ & 0.001 \\
\hline
\end{tabular}

$* \mathrm{p}<0.05$ is accepted to be statistically significant

The CA-125 levels in three categories of participants were: normotensive $(15.76 \pm 2.95)$, non-severe preeclampsia $(26.98 \pm 2.28), \quad$ severe pre-eclampsia $(44.99 \pm 11.23), \mathrm{p}<0.001$.
Table 2 shows significant positive correlations between maternal serum CA125 and the various clinical and laboratory markers of disease severity. 
Table 2: Correlation between CA125 and markers of severity for preeclampsia.

\begin{tabular}{|ll|l|}
\hline Parameters & $\begin{array}{l}\text { Pearson's co-efficient } \\
\text { of correlation }(\mathbf{r})\end{array}$ & P value \\
\hline $\begin{array}{l}\text { Systolic blood } \\
\text { pressure (mmHg) }\end{array}$ & 0.788 & 0.001 \\
\hline $\begin{array}{l}\text { Diastolic blood } \\
\text { pressure (mmHg) }\end{array}$ & 0.793 & 0.001 \\
\hline $\begin{array}{l}\text { 24 hours urinary } \\
\text { protein }\end{array}$ & 0.831 & 0.001 \\
\hline Platelet & -0.671 & 0.001 \\
\hline Birth weight & -0.542 & 0.001 \\
\hline
\end{tabular}

$* \mathrm{p}<0.05$ is accepted to be statistically significant

Table 3 shows association between CA125 and preeclampsia.

Table 3: Association between CA125 and preeclampsia.

\begin{tabular}{|llll|}
\hline Parameters & Normotensive & preeclampsia & Total \\
\hline $\begin{array}{l}\text { CA125 value } \\
<35 \text { IU/ml }\end{array}$ & 36 & 29 & 65 \\
\hline $\begin{array}{l}\text { CA125 value } \\
\mathbf{2 3 5} \text { IU/ml }\end{array}$ & 4 & 51 & 55 \\
\hline Total & 40 & 80 & 120 \\
\hline
\end{tabular}

Chi square value $=31.03, \mathrm{p}=0.001 *, * \mathrm{p}<0.05$ is accepted to be statistically significant

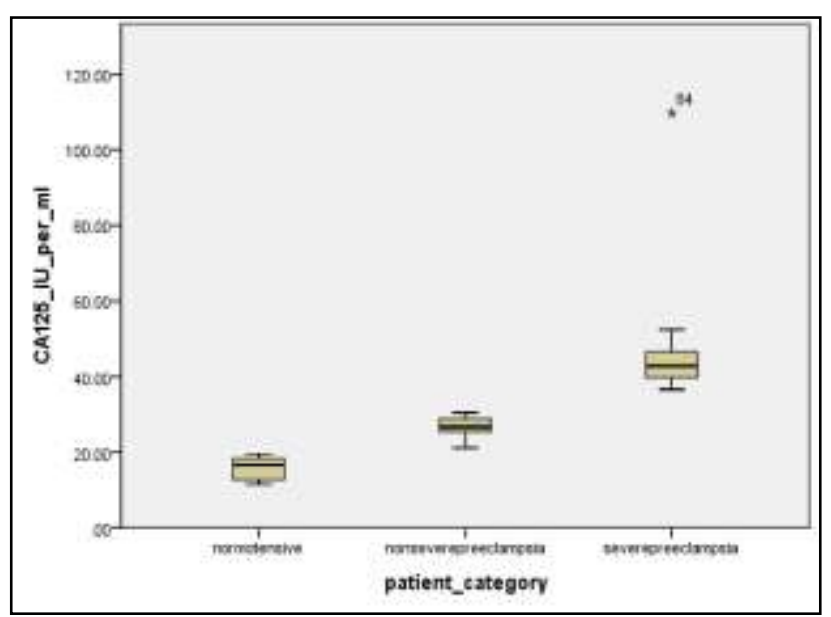

Figure 1: The distribution of $\mathrm{CA}-125$ values within the control group and patients with non severe and severe preeclampsia.

Figure 1 shows the distribution of CA-125 values within the control group and patients with non severe and severe preeclampsia. Women diagnosed with severe preeclampsia had significantly less parity and platelet counts whereas their systolic and diastolic blood pressure values as well as serum concentrations of uric acid and CA-125 were significantly higher. CA-125 levels correlated positively with systolic blood pressure $(\mathrm{r}=0.78$, $\mathrm{p}<0.001)$ (Figure 2), diastolic blood pressure $(\mathrm{r}=0.79$, $\mathrm{p}<0.001$ ) (Figure 3), negatively with platelet levels $(\mathrm{r}=-0.67, \mathrm{p}<0.001)$ (Figure 4) and with birth weight of baby $(\mathrm{r}=-0.54, \mathrm{p}<0.001)$ (Figure 5$)$. When cut-off for serum CA-125 levels was accepted as $35 \mathrm{IU} / \mathrm{ml}$, the sensitivity and specificity of the marker was found to be $92.1 \%$ and $97.1 \%$ respectively. Positive predictive value $95.5 \%$, negative predictive value $94.4 \%$.

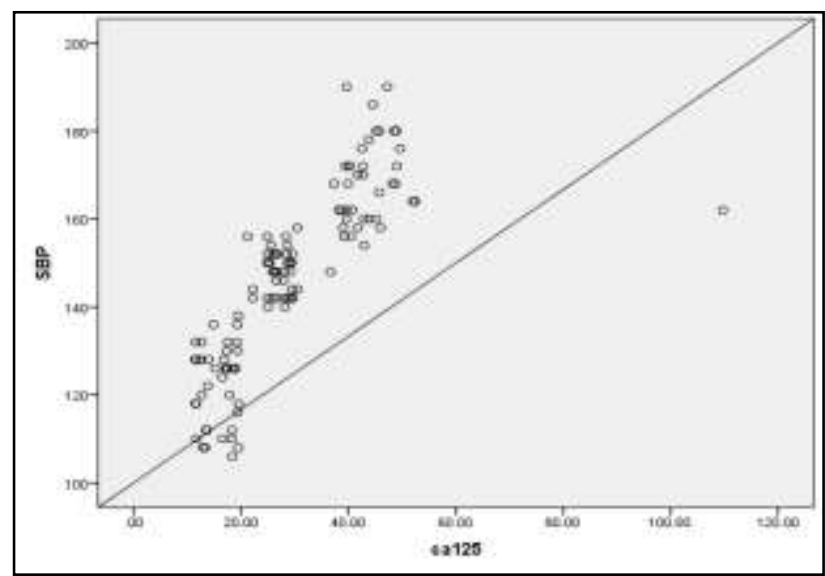

Figure 2: CA-125 levels correlated positively with systolic blood pressure $(r=0.78, p<0.001)$.

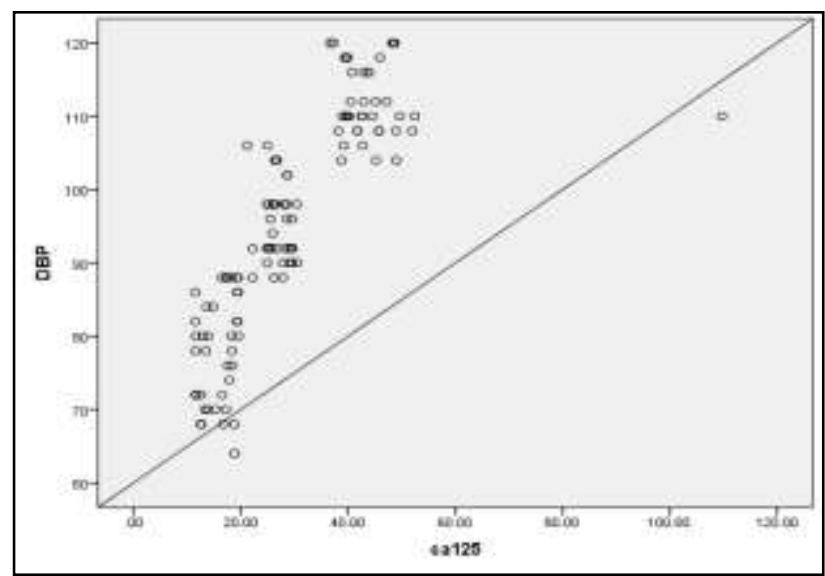

Figure 3: CA-125 levels correlated positively with diastolic blood pressure $(r=0.79, p<0.001)$.

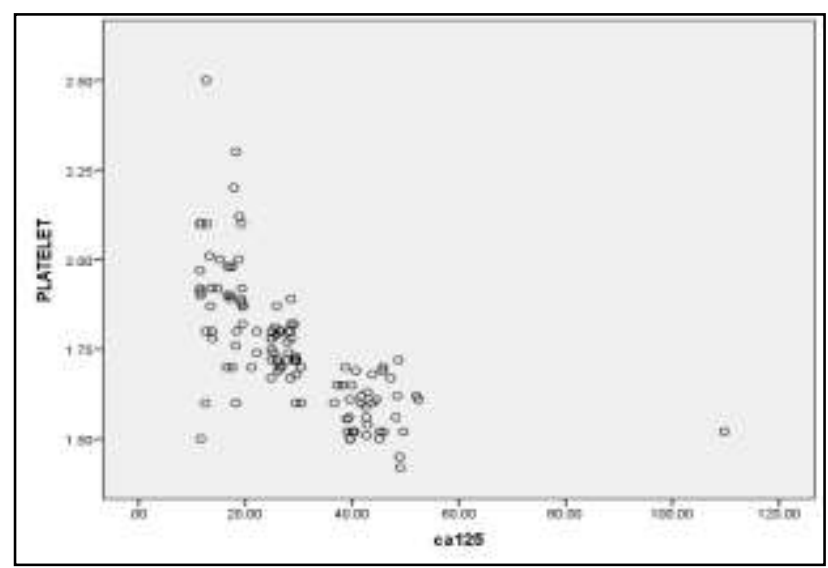

Figure 4: CA-125 levels correlated, negatively with platelet levels $(r=-0.67, p<0.001)$. 


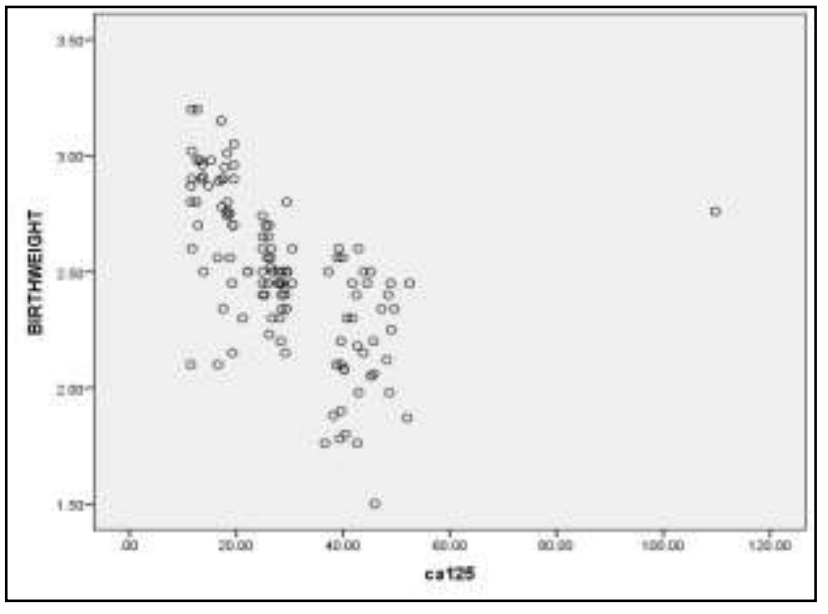

Figure 5: CA-125 levels correlated negatively with birth weight $(r=-0.54, p<0.001)$.

\section{DISCUSSION}

Several studies have examined the association between maternal serum CA 125 levels and preeclampsia, but these studies are widely unappreciated and less data regarding this are available in Indian population. Our study shows an elevated serum CA125 levels in preeclamptic pregnancy as compared with normotensive pregnancy and an even significantly higher levels in cases of severe preeclampsia, in similar fashion to the observations in previous studies by Karaman et al and Ozat et al. ${ }^{4,5}$ Present study also corroborates with Cebesoy et al who found a significantly higher serum concentrations of CA125 in women with preeclampsia. ${ }^{9}$ Cebesoy et al proposed that the elevation of CA125 in preeclampsia is probably due to ascites found in preeclamptic women arising from hypoalbuminemia, a theory also agreed by Karaman et al, Ozat et al on the other hand proposed the failure of trophoblastic invasion with the induction of an inflammatory process within the placenta leads to the expression of CA125 in preeclampsia. ${ }^{4,5,9}$

However, there occurs contradiction with some older studies. Schröcksnadel et al were the first to study the relationship between the plasma levels of CA125 in patients with hypertensive disorders of pregnancy, healthy pregnant and healthy non-pregnant controls but found no statistically significant differences in the three groups. ${ }^{6}$ Bon et al found that though maternal serum levels of CA125 were higher during the first and third trimesters of pregnancy, it showed no relationship with preeclampsia. ${ }^{7}$ De Groot et al in their study, examined CA125 levels of pregnant women (both normotensives and those who developed preeclampsia subsequently) over a time interval. ${ }^{8}$ They reported that CA125 did not differ with respect to their pregnancy outcome or gestational age but proposed a possible trend toward an elevation in CA125 concentrations for pregnancies that are certain to develop preeclampsia.
We have found that females diagnosed with preeclampsia have significant association with increase in systolic blood pressure, increase in diastolic blood pressure, 24 hours urinary protein levels. It has been deciphered from this study that increase in the severity of pre-eclampsia has negative association with maternal platelet levels and birth weight of the baby, and these are similar to the reports from other studies. ${ }^{4,5}$ Our findings thus emphasize the potential role of CA125 as biomarker or prognostic indicator of disease severity.

The limitation of this study was that it was institutionalbased, and thus the findings may not be representative of the general population.

\section{CONCLUSION}

We can determine from this study that increased maternal serum CA 125 levels is associated with the incidence of preeclampsia and it may play a role in determining the severity of disease. We, therefore, recommend that further validation of these findings with more robust longitudinal studies with maternal serum CA125 profiles in pregnancy to determine its suitability as a predictive biomarker for preeclampsia as well as to determine an acceptable cut-off value particularly amongst Indian women who have a propensity to present with severe disease and adverse pregnancy outcome.

\section{ACKNOWLEDGMENTS}

Authors acknowledge immense help received from the scholars whose articles are cited and included in the references of this manuscript. Authors are extremely thankful to all study subjects of this research who shared their valuable experiences and spent their precious time.

Funding: No funding sources

Conflict of interest: None declared

Ethical approval: The study was approved by the Institutional Ethics Committee of Bankura Sammilani Medical College

\section{REFERENCES}

1. Cunningham FG, Lenovo $\mathrm{K}$, Bloom S, Dashe J, Spong C, Hoffman B, et al. Williams Obstetrics. 25th edn. McGraw-Hill Education/ Medical; 2018: 710.

2. Khan KS, Wojdyla D, Say L, Gulmezoglu AM, Van Look PF. WHO analysis of causes of maternal death: A systematic review. Lancet. 2006;367(9516):1066.

3. Osanyin GE, Okunade KS, Ayotunde Oluwole A. Association between serum CA125 levels in preeclampsia and its severity among women in Lagos, South-West Nigeria. Hypertension in pregnancy. 2018;37(2):93-7.

4. Karaman E, Karaman Y, Alkis I, Han A, Yildrim G, Ark HC. Maternal serum CA125 level is elevated in 
severe preeclampsia. Pregnanc Hypertens. 2014;4(1):29-33.

5. Ozat M, Kanat-Pektas M, Okan Y, Tayfun G, Nuri D, Mollamahmutoglu L. Serum concentrations of CA-125nin normal and preeclamptic pregnancies. Arch Gynecol Obstet. 2010;284(3):607-12.

6. Schröcksnadel H, Daxenbichler G, Artner E, SteckelBerger G, Dapunt O. Tumor markers in hypertensive disorders of pregnancy. Gynecol Obstet Invest. 1993;35:204-8.

7. Bon GG, Kenemans P, Verstraeten AA, Go S, Philipi PA, Van Kamp GJ, et al. Maternal serum Ca125 and Ca15-3 antigen levels in normal and pathological pregnancy. Fetal Diagn Therap. 2001;16(3):166-72.
8. De Groot CJ, O'Brien TJ, Taylor RN. Biochemical evidence of impaired trophoblastic invasion of decidual stroma in women destined to have preeclampsia. Am J Obstet Gynecol. 1996;175(1):24-9.

9. Cebesoy FB, Ozcan B, Ebru D, Hakan K, Yelda I. CA125 and CRP are elevated in preeclampsia. Hypertens Pregnanc. 2009;28(2):201-11.

Cite this article as: Mukherjee B, Das A.

Association between serum ca-125 levels and severity of pre-eclampsia: a case-control study conducted in a tertiary care centre, West Bengal. Int J Reprod Contracept Obstet Gynecol 2020;9:4176-80. 